\title{
AVALIAÇÃO FÍSICA E QUÍMICA DE PRODUTOS MINIMAMENTE PROCESSADOS DE ABACAXI-'PÉROLA'1
}

\author{
BIANCA SARZI² \& JOSÉ FERNANDO DURIGAN ${ }^{3}$
}

\begin{abstract}
RESUMO - O objetivo deste trabalho foi avaliar, física e quimicamente, produtos minimamente processados de abacaxi-'Pérola', "rodelas" e "metades", armazenados sob diferentes temperaturas $\left(3^{\circ} \mathrm{C}, 6^{\circ} \mathrm{C} \mathrm{e} 9^{\circ} \mathrm{C}\right)$. Frutos selecionados, quanto ao grau de maturação e ausência de danos, foram lavados, desinfeccionados com cloro $\left(200 \mathrm{mg} . \mathrm{L}^{-1}\right)$ e armazenados a $10^{\circ} \mathrm{C}$, por 12 horas, antes do processamento. O produto minimamente processado foi embalado em bandejas de isopor recobertas com filme de PVC esticável ("metades") ou bandejas de tereftalato de polietileno ("rodelas") e armazenado sob refrigeração, com avaliação a cada 3 dias, quanto à textura, coloração, $\mathrm{pH}$, e conteúdos de sólidos solúveis totais, acidez total titulável, ácido ascórbico e de açúcares, solúveis e redutores. Durante o armazenamento, o produto tornou-se menos firme, e sua polpa apresentou escurecimento. Os conteúdos de açúcares solúveis e redutores e de sólidos solúveis totais não foram afetados pelo tipo de preparo, temperatura ou embalagem. Os teores de acidez total titulável aumentaram e foram influenciados pela temperatura, sendo que os mantidos a $9^{\circ} \mathrm{C}$ apresentaram os maiores teores, havendo, como consequiência, decréscimo no $\mathrm{pH}$. Os produtos armazenados a $9^{\circ} \mathrm{C}$ também apresentaram evolução mais rápida no escurecimento, na redução do teor de ácido ascórbico e menor vida útil (6 dias), enquanto, para os armazenados a $3^{\circ} \mathrm{C}$ e $6^{\circ} \mathrm{C}$, este período foi de 9 dias. Os resultados obtidos permitiram concluir que a temperatura de armazenamento foi o fator limitante para a vida útil destes produtos.
\end{abstract}

Termos de indexação: Ananas comosus, armazenamento, preparo, refrigeração

\section{PHYSICAL AND CHEMICAL STUDY OF MINIMALLY PROCESSED PRODUCTS OF 'PÉROLA' PINEAPPLES}

\begin{abstract}
The aim of the present study was to determine the physical and chemical characteristics of minimally processed products of 'Pérola' pineapples, "roundels" and "halves," stored under different temperatures $\left(3^{\circ} \mathrm{C}, 6^{\circ} \mathrm{C}\right.$ and $\left.9^{\circ} \mathrm{C}\right)$. The fruits, selected according to degree of maturation and absence of injury, were washed, disinfected with chlorine ( $\left.200 \mathrm{mg} . \mathrm{L}^{-1}\right)$ and stored at $10^{\circ} \mathrm{C}$ for 12 $\mathrm{h}$ before processing. The minimally processed product was packaged in styrofoam trays covered with a stretchable PVC film ("halves") or in polyethylene terephthlate trays ("roundels") and stored under refrigeration. The product was then examined every 3 days with regard to texture, coloration, $\mathrm{pH}$, and contents of total soluble solids, total titratable acidity, ascorbic acid and soluble and reducing sugars. During the storage, the product became less firm and its pulp appeared dark. The contents of the soluble and reducing sugars and total soluble solids weren't affected by the type of preparation, temperature or packaging. The levels of total titratable acidity increased and were influenced by the temperature, with those products kept at $9^{\circ} \mathrm{C}$ showing the highest levels, resulting in a decrease in $\mathrm{pH}$. The products stored at $9^{\circ} \mathrm{C}$ also showed a more rapid development in the dark, in the reduction of the level of ascorbic acid and a shorter shelf life ( 6 days), while for those stored at $3^{\circ} \mathrm{C}$ and $6^{\circ} \mathrm{C}$ this period was 9 days. From the results obtaineds, it could be concluded that the storage temperature is a limiting factor for the shelf life of these products.
\end{abstract}

Index terms: Ananas comosus, storage, preparation, refrigeration.

\section{INTRODUÇÃO}

O abacaxi, das cultivares 'Pérola' e 'Smooth Cayene', são bastante consumidos, tanto in natura como industrializados, pois apresentam ótima qualidade organoléptica, são boa fonte de vitaminas, açúcares e fibra, além de auxiliar no processo digestivo (Gonçalves e Carvalho, 2000). No Brasil, mais de 90\% do produzido é consumido in natura, com perdas de $10-15 \%$, de uma produção de 2,8 milhões toneladas, a qual se tem mantido estável nos últimos anos (Agrianual, 2001). Um dos fatores que tem impedido o aumento no consumo desta fruta é a sua falta de conveniência, uma vez que, para seu consumo, exige descasque trabalhoso e necessita de equipamento adequado, dado o escorrimento de líquidos e a dificuldade para redução dos pedaços.

O processamento mínimo de frutas e hortaliças é definido como sendo a operação que elimina as partes não comestíveis dos mesmos, como casca, talos e sementes, seguida do preparo em tamanhos menores e prontos para consumo imediato, sem que o vegetal perca a condição de produto fresco, com

1 (Trabalho 183/2001). Recebido: 19/11/2001. Aceito para publicação: 04/06/2002. Parte da Dissertação de Mestrado do primeiro autor. Financiado pela FAPESP processo $\mathrm{n}^{\circ}$ 12365-4.

2 Eng ${ }^{\mathrm{a}}$ Agr ${ }^{\mathrm{a}}$ Aluna de Doutorado do Departamento de Tecnologia da FCAV/UNESP, Jaboticabal. Via de acesso Prof. Paulo Donato Castellane, s/n, 14.884-900 Jaboticabal, SP - Telefone: (16) 3209-2675 -biasarzi@fcav.unesp.br

3 Prof. Titular do Departamento de Tecnologia da FCAV/UNESP Jaboticabal. Via de acesso Prof. Paulo Donato Castellane, s/n, 14.884-900 Jaboticabal, SP - Telefone: (16) 3209-2675 - jfduri@fcav.unesp.br 
qualidade e garantia de sanidade (Durigan, 2000).

O aumento no grau de conveniência do abacaxi, para os consumidores, poderia ser efetivado com sua comercialização já descascado e/ou na forma de "rodelas" e em embalagens que permitissem o consumo direto e facilitassem sua utilização em serviços de buffet, restaurantes ou lojas de fast food.

O presente trabalho teve como objetivo avaliar a manutenção da qualidade, durante o armazenamento refrigerado, de produtos minimamente processados de abacaxi-'Pérola'.

\section{MATERIAL E MÉTODOS}

Utilizaram-se frutos de abacaxi-'Pérola' produzidos em Frutal - MG, colhidos no ponto de maturação "pintado" (Classificação, 2000) e transportados 24 horas após a colheita para o Laboratório de Tecnologia dos Produtos Agrícolas da FCAV Jaboticabal - UNESP. Neste local, foram novamente selecionados, procurando tornar o lote ainda mais uniforme quanto ao grau de maturação e ausência de danos mecânicos ou podridões. Em seguida, as coroas foram retiradas e os frutos lavados com detergente neutro, tendo como ingrediente ativo o alquil- benzeno sulfonato de sódio, e água corrente e, em seguida, imersos, por 5 minutos, em água fria $\left(5^{\circ} \mathrm{C}\right)$ contendo $200 \mathrm{mg}$ de cloro. $\mathrm{L}^{-1}$, para desinfecção e retirada de parte do calor de campo. As frutas foram então mantidas em câmara fria $\left(10^{\circ} \mathrm{C}\right)$, previamente lavada e higienizada com solução de cloro a $200 \mathrm{mg} . \mathrm{L}^{-1}$, pelo período de 12 horas.

O processamento foi feito manualmente, com os utensílios, facas, baldes e escorredores previamente higienizados, com solução de cloro a $200 \mathrm{mg} . \mathrm{L}^{-1}$. Os operadores utilizaram luvas, aventais, gorros e máscaras, para proteger o produto de prováveis contaminações.

Os frutos foram descascados, sendo metade dos mesmos cortada em "rodelas" ( $1,5 \mathrm{~cm}$ de espessura) e a outra parte cortada em "metades", longitudinalmente. Estes produtos, depois de enxaguados com água sanitizada $\left(20 \mathrm{mg}\right.$ de cloro. $\left.\mathrm{L}^{-1}\right) \mathrm{e}$ escorridos por 2-3 minutos, foram embalados e armazenados sob refrigeração.

Para embalar o produto em "rodelas", utilizou-se a embalagem Neoform ${ }^{\circledR} \mathrm{n}^{\circ} 14$ de polietileno tereftalatado (PET) sem fechamento hermético, com as medidas $16,00 \mathrm{~cm} \times 17,00 \mathrm{~cm}$ x 9,00 $\mathrm{cm}$, e volume de 2,45 litros. Para embalar as "metades", utilizouse bandeja de isopor, com $0,50 \mathrm{~cm}$ de espessura e as dimensões $11,50 \mathrm{~cm} \times 19,00 \mathrm{~cm} \times 4,00 \mathrm{~cm}$, recoberta com filme de cloreto de polivinila (PVC) esticável e espessura de $0,017 \mathrm{~mm}$, e volume de 0,87 litros. Estes produtos foram armazenados a $3^{\circ} \mathrm{C}, 6^{\circ} \mathrm{C} \mathrm{e} 9^{\circ} \mathrm{C}$. A cada 3 dias, eles foram avaliados quanto à textura, determinada utilizando-se de penetrômetro FT 327 com ponteira de $8 \mathrm{~mm}$; coloração, determinada utilizando-se de reflectômetro Minolta Croma Meter CR-200b, que se expressa segundo o sistema proposto pela Commission Internacional de L'Eclaraige (CIE) em $\mathrm{L} * \mathrm{a} * \mathrm{~b} *$ (color space) o que permitiu calcular o ângulo Hue ou de cor $\left(\mathrm{h}^{\circ}\right)$, a luminosidade (L) e a cromaticidade (Croma); $\mathrm{pH}$, determinado através de potenciômetro (AOAC, 1997); e os conteúdos de sólidos solúveis totais, acidez total titulável, ácido ascórbico (AOAC, 1997), e de açúcares solúveis e redutores (Dubois et al., 1956, Villela et al., 1973). Avaliou-se, diariamente, a aparência, segundo uma escala de pontos, onde: 1=bom (aparência "fres- ca" e coloração natural); $2=$ regular (sinais de murchamento e/ou ressecamento e início de amolecimento); e 3=ruim (murchamento e/ou ressecamento, escurecimento e amolecimento).

O delineamento estatístico empregado foi o fatorial $2 \times 3$ (2 preparos e 3 temperaturas), com 6 tratamentos (épocas de amostragem) e 3 repetições, tendo como unidade experimental uma embalagem de produto (Gomes, 1982). A análise de variância e a comparação de médias foram feitas utilizando-se do programa computacional ESTAT da FCAV/UNESP.

\section{RESULTADOS E DISCUSSÃO}

O abacaxi-'Pérola' recém-processado caracterizou-se pelo bom teor de sólidos solúveis totais $\left(13,7 \pm 0,88^{\circ}\right.$ Brix $)$, que relacionado com o teor de acidez total titulável $(0,64 \pm 0,08 \mathrm{~g}$ de ácido cítrico. $100 \mathrm{~g} \mathrm{suco}^{-1}$ ), permite a comprovação de seu sabor doce (SST/ATT $=22,38 \pm 3,93$ ), além de apresentar adequado $\mathrm{pH}$ $(3,8 \pm 0,06)$, bom teor de ácido ascórbico $(21,81 \pm 5,41 \mathrm{mg} .100 \mathrm{~g}$ suco$\left.{ }^{1}\right)$ e textura suave $(13,2 \pm 0,07 \mathrm{~N})$. Estes resultados reafirmam os indicados por Gorgatti Netto et al. (1996), ou seja, acidez total titulável entre $0,60 \%$ e 1,62 \% de ácido cítrico, $\mathrm{pH}$ de 3,7 a 3,9 e teor de ácido ascórbico ao redor de 17,0 mg.100 g de polpa ${ }^{-1} \mathrm{e}$ por Giacomelli (1982), que encontrou 0,65-0,95\% de acidez total titulável e 14-16³rix.

A quantidade de açúcares solúveis mostrou-se bastante elevada $\left(12,66 \pm 2,22{\mathrm{~g} .100 \mathrm{~g}^{-}}^{1}\right)$, da qual cerca de $23 \%$ são redutores $\left(3,06 \pm 0,03 \mathrm{~g} \cdot 100 \mathrm{~g}^{-1}\right)$. Segundo Dull (1971), cerca de $66 \%$ de seus açúcares corresponde à sacarose, enquanto o teor de amido é bastante baixo $\left(0,49 \pm 0,09 \mathrm{~g} .100 \mathrm{~g}^{-1}\right)$. $O$ conteúdo de fibras, estimado através do resíduo da extração dos açúcares, foi de $1,36 \pm 0,07 \%$, o que está ao nível do relatado por Salunkhe e Desai (1984). Em relação à coloração da polpa, esta mostrou-se amarelo-clara, pouco pigmento $\left(\mathrm{L}=73,9 \pm 0,86, \mathrm{~h}^{\circ}=98,6^{\circ} \pm 0,28 \mathrm{e}\right.$ Croma $=19,2+1,41$ ).

Durante o armazenamento, não se observou amaciamento na textura da polpa, encontrado para outras frutas e que tem sido atribuído à modificação nas estruturas e na composição da parede celular pela ação de enzimas (Chitarra, 1999). Apesar de a textura não ter se modificado durante o armazenamento, as "metades" (7,9 N) apresentaram-se significativamente menos resistentes que as "rodelas" $(11,1 \mathrm{~N})$, sem que a temperatura influenciasse neste parâmetro.

Verificou-se que os tipos de preparo não influenciaram no escurecimento dos pedaços, mas a temperatura de armazenamento influenciou, pois, no $6^{\circ}$ dia, os pedaços mantidos a $9^{\circ} \mathrm{C}$ já apresentavam decréscimo significativo no valor $\mathrm{L}$, de 64,7 para 56,8 , indicando escurecimento. Os mantidos a $6^{\circ} \mathrm{C}$ só diferiram estatisticamente dos mantidos a $3^{\circ} \mathrm{C}$, no $12^{\circ} \mathrm{dia}(\mathrm{L}=$ 72,7 para os armazenados a $3^{\circ} \mathrm{C}$ e $\mathrm{L}=65,9$ para os a $6^{\circ} \mathrm{C}$ ). Tais dados concordam com O'Connor-Shaw et al. (1994), que avaliaram a qualidade sensorial de abacaxi minimamente processado, armazenado a $4^{\circ} \mathrm{C}$, e constataram que, no $11^{\circ}$ dia de armazenamento, os provadores detectaram escurecimento na polpa.

Constatou-se que a interação entre o tipo de preparo e a temperatura de armazenamento exerceu influência no escurecimento dos produtos, pois, aos 9 dias, as "rodelas" armazenadas a $9^{\circ} \mathrm{C}$ apresentavam-se mais escurecidas, e, aos 12

Rev. Bras. Frutic., Jaboticabal - SP, v. 24, n. 2, p. 333-337, agosto 2002 
dias, já haviam sido descartadas. Este escurecimento foi menor nas "metades" armazenadas a $6^{\circ} \mathrm{C}$.

Este escurecimento também foi observado por Martin et al. (1978) e por Chitarra (1999), que afirmam ser o processo de escurecimento decorrente de reações químicas e bioquímicas, conseqüentes ao processamento, principalmente devido ao contato das polifenoloxidases com seus substratos.

Os tipos de preparo influenciaram a cor, ou seja, até o $6^{\circ}$ dia, as "rodelas" apresentaram-se menos amarelas, ou com maiores valores para o ângulo hue $\left(98,3^{\circ}\right.$ para as "rodelas" e $95,0^{\circ}$ para as "metades"). A temperatura não teve influência na cor do produto. Constatou-se, também, que o tipo de preparo e a temperatura de armazenamento não tiveram influência na cromaticidade (14,0-15,0), ou seja, na quantidade de pigmentos.

Os abacaxis cortados em "rodelas" apresentaram menores teores de ácido ascórbico do que os cortados em "metades" (Tabela1). Isto mostra que, quanto maior o estresse causado pelo preparo, maior a perda desta vitamina, o que também foi observado por Chitarra (1999), que atribuiu esta maior perda ao aumento na atividade enzimática, e por Martin et al. (1978), que destacaram a importância da escolha dos equipamentos e dos métodos de processamento na manutenção das características iniciais do fruto.

Observou-se também, na Tabela 1 , que, quanto mais alta a temperatura de armazenamento, menor foi a conservação do teor de ácido ascórbico nos produtos, sendo que a $9^{\circ} \mathrm{C}$ este efeito foi significativamente prejudicial, confirmando Chitarra e Chitarra (1990). Não se observou interação significativa entre os parâmetros, preparo e temperatura, até o $9^{\circ}$ dia de armazenamento. A interação observada no $12^{\circ}$ dia não foi considerada como importante, pois os produtos já não se apresentavam comercializáveis.

Os teores de sólidos solúveis totais dos diferentes produtos apresentaram pequena variação, ou seja, mantiveram-se entre $12^{\circ}$ Brix e $14^{\circ}$ Brix. Pequenas variações também foram observadas por Singleton e Gotner (1965), pois o abacaxi tem metabolismo reduzido (Chitarra e Chitarra, 1990). Não se observaram diferenças atribuíveis ao preparo ou às temperaturas, mostrando que estes fatores não afetaram o conteúdo de sólidos solúveis totais dos produtos.

A variação nos teores médios de acidez total titulável são mostrados na Tabela 2 e indicam acréscimo durante o período de armazenamento, o que vem ao encontro de resultados obtidos para o 'Smooth Cayenne' (Silva, 1980). O tipo de preparo não mostrou efeito significativo neste conteúdo, mas a temperatura influiu significativamente. Os produtos mantidos a $9^{\circ} \mathrm{C}$ apresentaram os menores valores, indicando senescência mais rápida, e não se observou diferença entre as temperaturas de $3^{\circ} \mathrm{C}$ e $6^{\circ} \mathrm{C}$. Não se observou interação significativa entre os parâmetros, preparo e temperatura até o $9^{\circ}$ dia de armazenamento, com a interação observada no 12 dia não tendo sido considerada, pois os frutos já não se apresentavam comercializáveis.

O acréscimo na acidez titulável implicou decréscimo no $\mathrm{pH}$, pois as variações no $\mathrm{pH}$ traduzem as variações na acidez titulável (Teisson, 1979). O tipo de preparo e a temperatura de armazenamento não chegaram a afetar os valores de $\mathrm{pH}$, conforme o observado por Silva (1980), quando trabalhou com o armazenamento de abacaxis ao ambiente e sob refrigeração.

A relação entre os teores de sólidos solúveis totais e de acidez total titulável (SST/ATT) não foi influenciada pelo tipo de preparo, mas foi pela temperatura, ou seja, os produtos mantidos a $9^{\circ} \mathrm{C}$ apresentaram os maiores valores, como consequiência da redução nos seus teores de acidez. No entanto, o acréscimo ocorrido no conteúdo de acidez dos produtos armazenados a $3^{\circ} \mathrm{C}$ ou a $6^{\circ} \mathrm{C}$ levou a decréscimo nesta relação.

Observou-se uma pequena redução nos teores de açúcares solúveis, de $12 \%$ para $10 \%$, durante o armazenamento. Quanto aos conteúdos de açúcares redutores, observou-se um pequeno aumento, de $2,8 \%$ para $3,8 \%$, durante o armazenamento, o qual não foi afetado pela temperatura (dados não mostrados).

O conteúdo de resíduos da extração de carboidratos, que estima o teor de fibras do produto, foi maior no início do período de armazenamento, no produto em "rodelas" e no armazenado a temperaturas mais altas (dados não mostrados). Isto pode ser relacionado com a perda de suco pelo produto que sofreu corte mais drástico. Não se observou efeito interativo entre estes parâmetros.

A vida útil dos produtos foi limitada pela temperatura de armazenamento, pois os armazenados a $9^{\circ} \mathrm{C}$ apresentaram características comerciais até o $6^{\circ}$ dia, enquanto os armazenados a $3^{\circ} \mathrm{C}$ e $6^{\circ} \mathrm{C}$ permaneceram com estas características até o $9^{\circ}$ dia.

TABELA 1 - Conteúdos médios de ácido ascórbico (mg.100g de suco-1 $)^{*}$ em abacaxi-'Pérola' minimamente processado e armazenado sob diferentes temperaturas. Jaboticabal-SP, 2001.

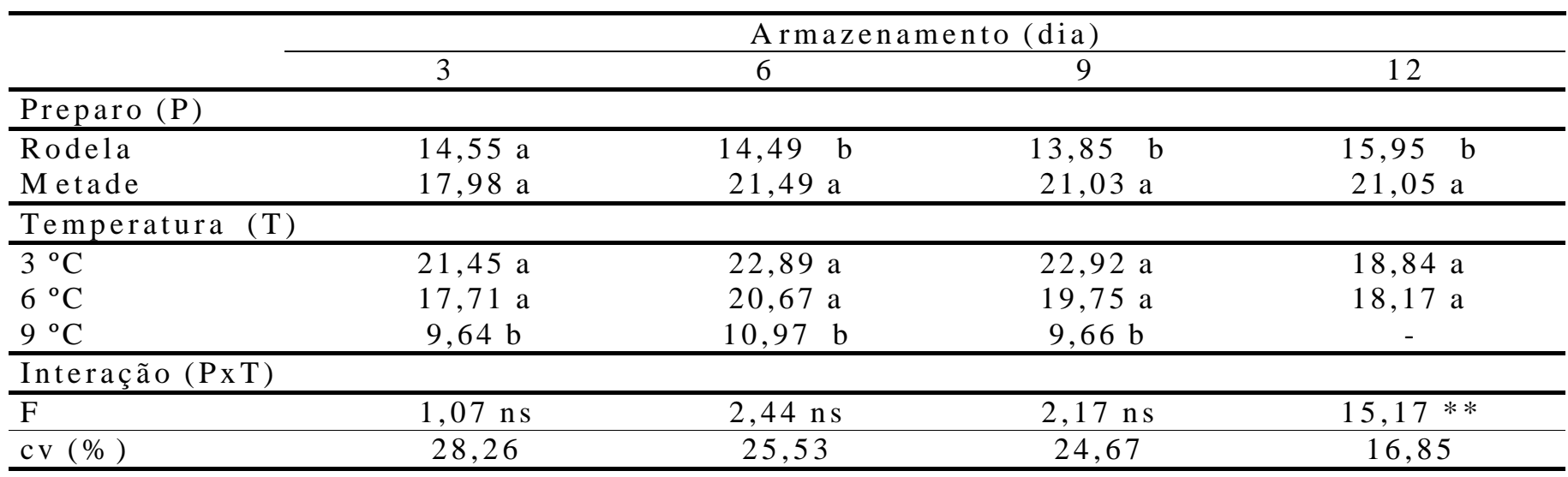

* Média na matéria prima $=21,81 \pm 5,41 \mathrm{mg} .100 \mathrm{~g}$ de $\mathrm{suco}^{-1}$

Médias seguidas de mesma letra, na coluna, não diferem significativamente entre si, ao nível de $5 \%$ de probabilidade, pelo teste de Tukey. 
TABELA 2 - Conteúdos médios de acidez total titulável (g de ácido cítrico.100g-1 de suco)* em abacaxi-'Pérola' minimamente processado e armazenado sob diferentes temperaturas. Jaboticabal-SP, 2001.

\begin{tabular}{lcccc}
\hline & \multicolumn{5}{c}{ Armazenamento (dia) } \\
\cline { 2 - 5 } & 3 & 6 & 9 & 12 \\
\hline Preparo (P) & $0,55 \mathrm{a}$ & $0,66 \mathrm{a}$ & $0,68 \mathrm{~b}$ & $0,84 \mathrm{a}$ \\
\hline Rodela & $0,59 \mathrm{a}$ & $0,76 \mathrm{a}$ & $0,81 \mathrm{a}$ & $0,85 \mathrm{a}$ \\
Metade & & & $0,92 \mathrm{a}$ & $0,86 \mathrm{a}$ \\
\hline Temperatura (T) & $0,64 \mathrm{a}$ & $0,77 \mathrm{a}$ & $0,83 \mathrm{a}$ \\
\hline $3{ }^{\circ} \mathrm{C}$ & $0,59 \mathrm{ab}$ & $0,83 \mathrm{a}$ & $0,84 \mathrm{a}$ & - \\
$6^{\circ} \mathrm{C}$ & $0,48 \mathrm{~b}$ & $0,54 \mathrm{~b}$ & & $0,48 \mathrm{~b}$ \\
$9{ }^{\circ} \mathrm{C}$ & & & $3,28 \mathrm{~ns}$ & $20,02 * *$ \\
\hline Interação (PxT) & $0,84 \mathrm{~ns}$ & $0,42 \mathrm{~ns}$ & 13,64 & 9,62 \\
\hline $\mathrm{F}$ & 16,86 & 19,15 &
\end{tabular}

- Média na matéria prima $=0,64 \pm 0,08 \mathrm{~g}$ de ácido cítrico.100g de suco $^{-1}$.

Médias seguidas de mesma letra, na vertical, não diferem significativamente entre si, ao nível de $5 \%$ de probabilidade, pelo teste de Tukey.

\section{CONCLUSÕES}

Os resultados obtidos permitem concluir que: 1. A manutenção da qualidade dos produtos minimamente processados de abacaxi-'Pérola' não foi influenciada pelo tipo de preparo.

2. A temperatura de armazenamento favoreceu o escurecimento, a redução nos teores de ácido ascórbico e de acidez total titulável e o aumento na relação SST/ATT, sendo, portanto, o fator decisivo no estabelecimento da vida útil deste produto.

\section{REFERÊNCIAS BIBLIOGRÁFICAS}

AGRIANUAL 2001. Anuário da agricultura brasileira. São Paulo: FNP Consultoria e Comércio, 2001. p. 139-147.

AOAC. Official methods of analysis of the Association of Official Analytical Chemists International. 16. ed. Washington: AOAC, 1997.v.2, p.37-10, 42-2, 44-3, 45-16.

CHITARRA, M. I. F.; CHITARRA, A. B. Pós-colheita de frutos e hortaliças: fisiologia e manuseio. Lavras: ESAL/Fundação de Apoio ao Ensino, Pesquisa e Extensão, 1990. 293p.

CHITARRA, M. I. F. Alterações bioquímicas do tecido vegetal com o processamento mínimo. In: SEMINÁRIO SOBRE HORTALIÇAS MINIMAMENTE PROCESSADAS, 1999, Piracicaba. Palestra... Piracicaba: ESALQ-USP, 1999. 9p. Apostila.

CLASSIFICAÇÃO do abacaxi (Ananas comosus (L.) Merril). Recife: Centro de qualidade em Horticultura CEAGESP, 2000. Fôlder.

DUBOIS, M.; GILLES, K.A.; HAMILTON, J.K.; REBER, P.A.; SMITH, F. Colorimetric method for determination of sugar and related substances. Analytical Chemistry, Washington, v.2, n.3, p. 350-356, 1956.

DULL, G. G. The pineapple: general. In: HULME, A. C. (Ed.) The biochemistry of fruits and their products. England: Academic
Press, 1971. v.2, p.303-324.

DURIGAN, J. F. O processamento mínimo de frutas. In: CONGRESSO BRASILEIRO DE FRUTICULTURA, 16., 2000, Fortaleza. Palestra...Fortaleza: Sociedade Brasileira de Fruticultura, 2000. $12 p$.

GIACOMELLI, E. J.Expansão da abacaxicultura no Brasil.Campinas: Fundação Cargill, 1982.72p.

GOMES, F.P. Curso de estatística experimental. 10.ed. Piracicaba: Nobel, 1982. 430p.

GONÇALVES, N.B.; CARVALHO, V.D. de. Características da fruta. In: GONÇALVES, N.B.(Org.) Abacaxi: pós-colheita. Brasília: Embrapa Comunicação para Transferência de Tecnologia. 2000. cap. 2, p.13-27 (Frutas do Brasil, 5).

GORGATTI NETTO, A.; CARVALHO, V.D. de; BOTREL, N.; BLEINROTH, E.W.; MATALHA, M.; GARCIA, A.E.; ARDITO, E.F.G.; GARCIA, E.E.C.; BORDIN, M.R. Abacaxi para exportação: procedimentos de colheita e pós-colheita, Brasília: EMBRAPA - SPI, 1996.41p. (Série Publicações Técnicas FRUPEX, 23).

MARTIN, Z.J.de; SOUZA JUNIOR, A.J.de; LARA, J.C.C.; HASHIZUME, T. Processamento: produtos e subprodutos, características e utilização. In: MEDINA, J.C.; BLEINROTH, E.W.; MARTIN, Z.J. de; SOUZA JUNIOR, A.J. de; LARA J.C.de; HASHIZUMET, T.; MORETTI, V.A.; MARQUES, J.F. Abacaxi: da cultura ao processamento. Campinas: ITAL, 1978. p.69-94.

O'CONNOR-SHAW, R. L.; ROBERTS, R.; FORD, A.L.; NOTTINGHAM, S.M. Shelf life of Minimally Processed honeydew, kiwifruit, papaya, pineapple and cantaloupe. Journal of Food Science, Chicago, v.59, n.6, p. 1202-1215, 1994.

SALUNKHE, D. K.; DESAI, B. B. Postharvest biotechnology of fruits. Boca Raton: CRC Press, 1984. v.2, 194p.

SILVA, M. A. Fisiologia pós-colheita de abacaxi cvs. Pérola e Smooth Cayenne. 1980. 203f. Dissertação (Mestrado em Enge-

Rev. Bras. Frutic., Jaboticabal - SP, v. 24, n. 2, p. 333-337, agosto 2002 
nharia Agrícola) - Faculdade de Engenharia Agrícola, Universidade Estadual de Campinas, Campinas, 1980.

SINGLETON, V. L.; GORTNER, W. A. Chemical and physical development of the pineapple fruit. II Carbohydrate and acid constituents. Journal of Food Science, Chicago, v.30, n.1, p.19-23, 1965.
TEISSON, C. Le brunissement interne de ananas. I - Historique. II - Materia et métodes. Fruits, Paris, v.34, n.4, p.245-261, 1979. VILLELA, G.; BACILA, M.; TASTALDI, H. Técnicas e experimentos de bioquímica. Rio de Janeiro: Guanabara - Koogam, 1973. 552p. 